\title{
A gestão das gerações em uma empresa que nasceu "Y" nos anos 1960: Os papéis funcionais em sobreposição à idade
}

\author{
Management of generations in a company that was born " $Y$ " in the \\ I960's decade: Roles overlapping age
}

Rodrigo Cunha da Silva ${ }^{\mathrm{I}}$ Joel Souza Dutra ${ }^{2}$

\section{Resumo}

Elza Fátima Rosa Veloso ${ }^{3}$

O objetivo deste artigo é o de explorar os fatores contextuais e a gestão das gerações em uma empresa que é referência em gestão de pessoas no Brasil. Para o cumprimento de tal objetivo, foi realizada uma pesquisa descritiva-explicativa, consolidada por meio de um estudo de caso na Promon S.A.Constatou-se que o contexto em que a gestão de pessoas acontece influencia a gestão das gerações. Tal influência parece impossibilitar a criação de apenas um padrão para tal gestão, tornando ainda mais desafiadora a tarefa de promover a convivência inevitável entre as gerações.

Palavras-chave: Geração Y, Organização, Gestão de Pessoas.

\begin{abstract}
The purpose of this article is to explore the contextual factors and management of generations in a company that is a reference in human resource management in Brazil. To fulfill this goal we performed a descriptive-explanatory, consolidated through a case study in Promon SA was found that the context in which people management happens influences the management of generations. Such influence seems impossible to create only a standard for management, making it even more challenging task of promoting coexistence between generations inevitable.
\end{abstract}

Keyword: Generation Y, Organization, Human Resource Management.

\footnotetext{
1 rdgcdasilva@gmail.com, Brasil. Professor da Fundação Instituto de Administração - FIA. Doutorando em Administração na Universidade de São Paulo - USP. Av. Prof. Luciano Gualberto, 908, Cidade Universitária, CEP: 05508-900 - São Paulo, SP - Brasil.

2 jdutra@usp.br, Brasil. Professor da Livre Docente da Universidade de São Paulo - USP. Doutor em Administração pela Universidade de São Paulo - USP. Av. Prof. Luciano Gualberto, 908, Cidade Universitária, CEP: 05508-900 - São Paulo, SP - Brasil.

3 elzafr@uol.com.br, Brasil. Professora do Centro Universitário das Faculdades Metropolitanas Unidas - FMU. Doutora em Administração pela Universidade de São Paulo - USP. Rua Taguá, 150, Liberdade, CEP: 01508-010 - São Paulo, SP Brasil.
}

Recebido em 29.08.2013

Aprovado em 04.12.2013

Revista Administração em Diálogo ISSN 2178-0080 


\section{Introdução}

O Instituto de Pesquisa Econômica Aplicada - IPEA (20I2) indica que, entre I992 e 2OII, as taxas de participação na força de trabalho brasileira aumentaram, tanto para os indivíduos com idade entre 25 e 49 anos, quanto para os com 5 o anos ou mais e que essas taxas tendem a continuar aumentando até 2030. O incremento do número de indivíduos com mais de $5^{\mathrm{O}}$ anos na força de trabalho, segundo esse instituto, pode ser explicado pelo aumento desse grupo no total da população brasileira, em decorrência de uma maior expectativa de vida.

$\mathrm{O}$ fato de que pessoas com mais de $5 \mathrm{O}$ anos continuam se inserindo no mercado de trabalho, paralelamente ao fenômeno natural de inserção dos jovens, contradiz o raciocínio de que os profissionais mais velhos se aposentariam para ceder lugar a profissionais mais jovens. Tal fenômeno provoca reflexões sobre as novas configurações do ambiente organizacional contemporâneo. De forma geral, novas estruturas organizacionais, mais horizontalizadas e em espaços mais compactos, estão forçando a convivência entre pessoas de idades muito diversas no ambiente de trabalho (MEISTER; WILLYERD, 20IO). Nesse sentido, pesquisadores alertam para o fato de que essa maior proximidade tem o potencial de gerar conflitos entre os diversos grupos geracionais presentes nas organizações, em função de seus diferentes valores, ambições, visões e pré-concepções (MEISTER; WILLYERD, 2oIO; MCGUIRE; TODNEM; HUTCHINGS, 2007; ZEMKE et al., 2000).

Na literatura sobre gerações, é comum encontrar três classificações, baseadas em idade: Baby boomer, geração X e geração Y (PARRY; URWIN, 2OII; WESTERMAN; YAMAMURA, 2007). A geração Baby boomer (com nascimento entre I946 e I964) é composta por pessoas que acreditam em empregos para uma vida toda e demonstram lealdade à organização na qual trabalham. As pessoas da geração X (nascidas entre ${ }_{9} 65 \mathrm{e}$ I980) mostram-se descrentes e desconfiadas em relação às organizações, assim, eles não compartilham o mesmo compromisso dos Baby boomers com as organizações em que trabalham. Já a geração Y (composta por pessoas nascidas entre i980 e 1994) tende demonstrar atitudes de inquietação, contestação e, às vezes, de insubordinação sobre diversos aspectos do cotidiano das organizações (VELOSO, 20I2; VELOSO; SILVA; DUTRA, 2OI2). 
Apesar da forte participação dos Baby boomers e da Geração X nas empresas, a Geração Y tem chamado a atenção de gestores e acadêmicos, por suas características comportamentais. Normalmente, esses jovens são caracterizados pela relutância em obedecer à hierarquia organizacional, porém, desejam uma direção clara e apoio da gestão às suas atividades; procuram flexibilidade e autonomia na realização de tarefas e possuem a vantagem de lidar, habilmente, com novas tecnologias. (COIMBRA; SCHIKMANN, 2OOI). Esses profissionais valorizam, em suas carreiras, o aprendizado, o desenvolvimento, a identificação com o trabalho e o equilíbrio entre vida pessoal e profissional. Além disso, são mais críticos sobre o cotidiano das organizações e o uso das relações interpessoais como meios de ascensão na carreira (VELOSO; DUTRA; SILVA, 2012). Algumas empresas, por seu estilo de gestão, parecem ter características adequadas a essa geração, embora tenham sido fundadas em décadas anteriores. A empresa escolhida para o estudo apresentado neste artigo, a Promon S.A, é uma dessas empresas. Apesar de ter sido fundada nos anos 1960, apresenta características de flexibilidade e dinamismo em sua gestão de pessoas que, certamente, influenciam maneira como a gestão das gerações acontece.

Em coerência com os indícios de que a maneira como a gestão de pessoas é organizada influencia a gestão das gerações, o objetivo deste artigo é o de explorar os fatores contextuais e a gestão das gerações em uma empresa que é referência em gestão de pessoas no Brasil. Para o cumprimento de tal objetivo, foi realizada uma pesquisa descritiva-explicativa, consolidada por meio de um estudo de caso na Promon S.A. Além desta introdução e das considerações finais, este artigo está dividido em quatro seções. Na próxima seção é apresentado o referencial teórico que sustentou o estudo; na seção seguinte, a metodologia que orientou a pesquisa é detalhada; em seguida, está posicionada a seção em que os resultados são apresentados. Por fim, é exposta a seção em que os resultados são discutidos.

\section{Referencial Teórico}

Nesta seção, são apresentadas as reflexões teóricas e conceituais que sustentam a pesquisa apresentada neste artigo, iniciando com reflexões sobre os determinantes da 
identidade geracional. Em seguida, é apresentada a relação entre fatores contextuais e gerações.

\section{Os determinantes da identidade geracional}

Em geral, nos estudos relacionados à gestão de pessoas, a noção de gerações é embasada pelos pressupostos teóricos de Manheim, pois os estudos desse autor se referem a grupos de pessoas que, por terem nascido em uma determinada época, vivenciaram eventos históricos e sociais significantes em estágios cruciais do seu desenvolvimento, os quais influenciaram sobremaneira seus valores, suas atitudes e suas crenças (WESTERMAN; YAMAMURA, 2OOZ).

De acordo com Joshi et al. (2OIO), além da abordagem de Manheim para os estudos sobre gerações,baseadas em idade, existem outras duas: coorte e incumbência de papéis.Nesse sentido, os autores introduzem o conceito de identidade geracional como o conhecimento de um indivíduo acerca de um grupo ou papel. As abordagens descritas por esses autores são as seguintes:

Identidade geracional baseada em coorte: Nessa visão, as gerações são definidas por grupos de pessoas que entraram no mesmo instante em determinada situação, tal como um grupo de alunos que, ao mesmo tempo, inicia um semestre num sistema de ensino. As interações entre as gerações anteriores e posteriores são susceptíveis de serem influenciadas pelo acesso ou controle sobre um conjunto de competências ou recursos valiosos, ou por um conjunto único de experiências, que uma geração adquiriu no decorrer do tempo. A identidade geracional baseada em coorte baseia-se na associação de um conjunto compartilhado de experiências organizacionais.

Identidade geracional baseada em incumbência de papéis: A incumbência de papel está associada com um conjunto de experiências, atitudes, conhecimentos e capacidades formadas como resultado de um trabalho ou papel ocupado em uma quantidade finita de tempo. Assim, os processos sócio-cognitivos, associados à incumbência em um papel, diferem das identidades baseadas em coorte e idade, cuja adesão é estável e imutável.

As identidades geracionais podem ser caracterizadas pela participação em grupos baseados em idade e coorte, bem como em papéis organizacionais (como 
supervisor e subordinado). Para Joshi et al. (20IO), os três tipos de identidades geracionais podem coexistir em uma organização, no entanto, a primazia de uma identidade particular e da natureza das interações entre gerações associadas a esta identidade são dependentes do contexto organizacional.

Além do entendimento das identidades geracionais, é importante entender o contexto em que a gestão das gerações acontece.

\section{A relação entre os fatores contextuais e as gerações}

De acordo com Joshi et al. (2OIO), nas organizações, os fenômenos geracionais podem se manifestar de várias maneiras e terem várias consequências. Embora contexto organizacional possa ser caracterizado por vários fatores, os autores consideram os contextos estruturais e normativos essenciais para sua compreensão. O contexto estrutural é baseado na noção de sistemas mecânicos e orgânicos, de Burns e Stalker (I96I). Já o segundo contexto, o normativo, é caracterizado como o entendimento compartilhado das políticas, práticas, procedimentos, objetivos e comportamento esperados pela organização e que merecem ser recompensados (BOWEN; OSTROFF, 2004; MISCHEL, 1973).

Contextos normativos fortes são criados quando levam as pessoas a perceber os eventos da mesma forma, induzem expectativas uniformes sobre o comportamento mais adequado e indicam quais são as competências necessárias para realizar esse comportamento. Por outro lado, as pessoas em contextos normativos fracos não percebem os eventos da mesma forma e as expectativas sobre o comportamento adequado são inconsistentes ou mesmo inexistentes (BOWEN; OSTROFF, 2004; MISCHEL, I973).

Em qualquer situação, de acordo com os autores mencionados, a pessoa adota o padrão de resposta que ela espera ser mais susceptível à condução de resultados que ela acredita serem desejáveis; com base nessas constatações, surge a noção da força dos sistemas de gestão de pessoas. Bowen e Ostroff (20O4) propõem que, quando um sistema de gestão de Recursos Humanos (RH) é caracterizado por alta distinção, consistência e consenso, ele tende criar um contexto forte. Esses três fatores são explicados pelos autores da seguinte forma: 
Distinção: Refere-se aos recursos que se destacam no ambiente, capturam a atenção e despertam interesse.

Consistência: Está relacionada à permanência do efeito das práticas de recursos humanos ao longo do tempo. Refere-se ao estabelecimento da percepção da relação de causa e efeito com referência ao sistema de gestão de recursos humanos, garantindo que os incentivos estão adequadamente associados ao desempenho desejado de comportamento.

Consenso: O consenso resulta do acordo entre os funcionários e o sistema de gestão de recursos humanos. Quando as atribuições dos empregados são precisas sobre quais comportamentos levam a determinadas consequências, maior é a chance de haver consenso.

De forma geral, nas organizações, cabe ao modelo de gestão de pessoas, gerenciar e orientar o comportamento humano no trabalho (FISCHER, 2002). Neste estudo, as políticas e práticas de gestão de pessoas merecem destaque por serem os elementos mais visíveis desse modelo (DEMO, 2008).

\section{O papel das políticas e práticas de gestão de pessoas no desafio de gerir gerações}

Para Boxall \& Purcell (2000), a gestão de recursos humanos diz respeito a tudo e qualquer coisa associada com a gestão das relações entre trabalhadores e organização. Os seus principais desafios seriam responder questões relacionadas sobre quais políticas e práticas seriam adequadas para melhorar o desempenho da empresa e da própria função de recursos humanos.

Martín-Alcázar et al. (2005) propõem uma definição integrada para gestão estratégica de recursos humanos, que considera o sistema de gestão de pessoas como um “conjunto integrado de práticas, políticas e estratégias por meio das quais as organizações gerenciam o seu capital humano, que influencia e é influenciado pela estratégia de negócio, contexto organizacional e socioeconômico" (MARTíNALCÁZAR et al., 2005, p. 65I).

Nesse sentido, no Brasil, segundo Wood Jr, Tonelli e Cooke (2OII), a análise das políticas e práticas de gestão de pessoas deve ser complementada pela perspectiva do contexto social e cultural brasileiro. 
Fiuza (2OIO) realizou um estudo sobre a literatura nacional e internacional no período compreendido entre 2004 e 2008. A autora aponta as seguintes políticas de gestão de pessoas mais estudadas nesse período, nessa ordem: treinamento, desenvolvimento e educação, condições de trabalho, envolvimento e remuneração/recompensas. A autora afirma que, dependendo dos valores das pessoas, da percepção de justiça organizacional e do tipo de organização em que trabalham, certas políticas de gestão de pessoas são mais percebidas e, possivelmente, devem ser mais adequadas e eficazes no alcance dos objetivos organizacionais, bem como na promoção de um maior bem-estar dos colaboradores. A autora também mostra que a percepção de justiça organizacional é forte preditora da percepção de políticas de gestão de pessoas. Por conseguinte, a autora entende como relevante a consideração de tais questões quando do desenvolvimento de políticas de gestão de pessoas nas organizações.

Por outro lado, as políticas e práticas de gestão de pessoas também têm a capacidade de influenciar a percepção dos empregados (VELOSO et al., 2OII; SILVA et al., 2OIO). Portanto, deve-se considerar um ajuste adequado entre políticas e práticas e características pessoais dos empregados (WERBEL; DEMARIE, 2005).

Tendo em vista tal influência, a adequação dos sistemas de gestão de recursos humanos em um cenário de permanência dos Baby boomers, consolidação da Geração X em posições intermediárias, e entrada da Geração Y, torna premente a consideração das diferenças e similaridades de cada geração na gestão de pessoas. Preferencialmente, os sistemas de gestão de pessoas deveriam atender aos anseios das gerações e influenciar a integração entre elas, por meio do seu conjunto de políticas e práticas (MARTÍNALCÁZAR et al., 2005; MCGUIRE et al., 2007; LEPAK; SHAW, 2008; MEISTER; WILLYERD, 2OIO).

Conforme os estudiosos de gerações recomendam, deve-se evitar a criação de feudos geracionais dentro das organizações. Sempre que possível, as gerações devem ser incentivadas a interagir como meio para o compartilhamento de experiências no trabalho (MCGUIRE et al., 2007; MEISTER; WILLYERD, 2OIO). Nesse sentido, iniciativas de gestão de pessoas no ambiente de trabalho podem ser organizadas para facilitar uma maior interação geracional, bem como um ambiente de trabalho favorável (MCGUIRE $e t$ al., 20O7; MEISTER; WILLYERD, 2OIO). A seguir, estão expostos três modelos atuais, 
sendo o modelo de Mcguire et al. (2007) e Joshi et al.(2010) embasado pelo meio acadêmico, e, o de Meister e Willyerd (20IO), pelo meio empresarial.

O modelo de Mcguire et.al. (2007) trata da dinâmica da interação entre os grupos geracionais e dos modos de intervenção da gestão de pessoas. Meister e Willyerd (20IO) buscam propor princípios, políticas e práticas de gestão de pessoas que estejam alinhados aos anseios das gerações. Já o modelo de Joshi et. al (20IO) adota uma abordagem multi-geracional, que considera a influência do contexto organizacional nas interações entre as pessoas. Joshi et al. (2OIO) sugerem que o contexto estrutural e normativo agem conjuntamente e influenciam a ativação de uma determinada identidade e a interação geracional.

Nas organizações caracterizadas por um sistema mecânico de gestão (BURNS; STALKER, I96I) e um contexto normativo forte, os trabalhos são especializados e hierarquicamente definidos. Organizações mecanicistas que enfatizam um contexto normativo forte também realizam treinamentos, avaliação e monitoramento do desempenho dos empregados. A formação e o acompanhamento do desempenho são formas de melhorar a compreensão e interpretação dos empregados sobre seus objetivos, normas e responsabilidades. Estas condições, segundo Joshi et al. (20IO), favorecem a prevalência da identidade geracional baseada em coortes em comparação com outras identidades porque os empregados, muitas vezes de idade semelhante, entram na organização mais ou menos ao mesmo tempo. Os processos relacionais subjacentes a uma identidade geracional baseada em coorte seriam baseados em diferenças de competências e experiências de socialização. Por outro lado, nas organizações caracterizadas por uma estrutura orgânica e um contexto normativo forte, há maior valorização das competências que os indivíduos trazem para uma determinada função do que em habilidades específicas adquiridas ao longo do tempo na empresa. Tais condições reforçam a prevalência de uma identidade geracional baseada em incumbência de papéis BURNS; STALKER, I96I; JOSHI et al., 20Iо).

A prevalência de diferenças geracionais baseadas idade seriam mais prováveis de ocorrer em organizações mecanicistas, onde os trabalhos são organizados hierarquicamente e os empregados, geralmente, começam em níveis mais baixos e progridem na carreira, conforme o tempo de empresa e vagas em aberto. Essas 
características tendem a enfatizar uma correlação entre idade e cargo. Já em contextos fracos, caracterizados pela falta de consenso e de compreensão compartilhada das políticas organizacionais, práticas, objetivos, recompensas e comportamentos esperados, os empregados recorreriam aos valores desenvolvidos durante seus anos de formação, em vez de experiências de socialização organizacional (JOSHI et al., 2OIO).

\section{Metodologia}

Segundo Gil (20IO, p.28), “algumas pesquisas descritivas vão além da simples identificação da existência de relações entre variáveis e pretendem determinar a natureza dessa relação. Nesse caso, tem-se uma pesquisa descritiva que se aproxima da explicativa”. Portanto, o presente trabalho classifica-se como uma pesquisa de natureza descritiva-explicativa (BERVIAN; CERVO; SILVA, 2007; GIL, 2OIO), consolidada por meio da realização de um estudo de caso.

\section{O estudo de caso}

O estudo de caso é uma estratégia de pesquisa que busca o entendimento de determinada dinâmica em configurações únicas. Podem ser analisados mais de um, os chamados estudos multicasos, ou um único caso, com mais de um nível de análise. Os estudos de caso podem ser utilizados para o cumprimento de objetivos diversos, que podem ser tanto descritivos quanto para testar ou gerar alguma teoria (EISENHARDT, 1989). Esta pesquisa pode ser classificada como um estudo de caso único, com somente um nível de análise: a área de gestão de pessoas da organização. Para a realização do estudo, adotou-se a abordagem qualitativa, por meio da triangulação dos dados (EISENHARDT, I989; YIN, 2OOI).

Além da entrevista com o responsável pela função de gestão de pessoas da organização, foram estudadas as descrições de políticas e práticas relativas à gestão de gerações, disponibilizada em um documento (Cadernos de Evidências), elaborado pela empresa selecionada com o intuito original de participar da pesquisa "As Melhores Empresas para Você Trabalhar" (pesquisa MEPVT), publicada anualmente por uma grande editora brasileira, com metodologia sob responsabilidade de uma importante escola de negócios da cidade de São Paulo. Ressalta-se que o material dessa pesquisa 
serviu de base para outros trabalhos acadêmicos sobre o tema gerações (VELOSO, 2OI2; VELOSO; NAKATA; DUTRA, 20o8; VELOSO; SILVA; DUTRA, 20I2;) e que esse fato impulsionou a apreciação desse material para a realização do estudo apresentado neste artigo. A importância da pesquisa MEPVT consiste no fato de que as empresas concorrem para se destacar no mercado brasileiro em termos de clima organizacional positivo e boas práticas de gestão de pessoas.

Como complemento, documentos públicos foram analisados por meio do website da empresa e o Relatório de Gestão de 2OII. A entrevista foi realizada pessoalmente em abril de $20 \mathrm{O} 3$ utilizando questões específicas do roteiro de entrevista elaborado com o apoio do referencial teórico apresentado neste artigo.

Para análise e interpretação dos dados obtidos na entrevista e na documentação da pesquisa MEPVT, foi utilizada a análise de conteúdo. Tendo como referência a proposta de Bardin (2002) e de Mozzato e Grzybovski (2OII), a análise de conteúdo pode ser considerada um conjunto de técnicas de análise de comunicações, que tem como objetivo ultrapassar as incertezas e enriquecer a leitura dos dados coletados. Quatro etapas foram organizadas para análise de conteúdo após o recolhimento do material documental e a transcrição da entrevista: pré-análise, codificação e categorização, e inferência.

É importante ressaltar que, para garantir o rigor metodológico do estudo de caso, foram seguidos os quatro critérios de avaliação sugeridos por Gibbert, Ruigrok e Wicki (2008): validade interna, validade de construto, validade externa e confiabilidade.

\section{Organização estudada: Promon}

A organização selecionada para o estudo foi Promon S.A, que representa a unidade de análise do estudo de caso.

O critério inicial para seleção foi a organização apresentar evidências de ter um contexto forte de gestão de pessoas. A sua participação, figurando entre as Melhores Empresas para se Trabalhar, na pesquisa MEPVT, em todas as edições da publicação, de I997 a 20I2, foi o principal indicador desse critério. Vale ressaltar que apenas três organizações atenderam a esse critério, sendo Promon uma delas. A entrevistada, 
responsável pela área de gestão de pessoas, foi a diretora de relações humanas e comunicação.

O segundo critério de escolha foi o contexto estrutural, classificado conforme o tipo de sistema organizacional. Conforme Burns \&Stalker (I96I), o surgimento de sistemas mecanicistas e orgânicos de gestão são resultados da influência de variáveis ambientais, referentes à tecnologia de produção e à situação de mercado de determinada organização. No que diz respeito a essas duas variáveis, foi possível partir para a pesquisa de campo já com conhecimento prévio de que Promon, por trabalhar apenas com o serviço de elaboração de soluções customizadas de engenharia, tenderia ao sistema orgânico.

Assim, foi possível obter diferentes elementos para análise dos contextos estruturais e normativos sob a perspectiva do modelo teórico proposto para a pesquisa. Porém, houve a necessidade de que a organização apresentasse indícios de contexto forte de gestão de pessoas, para que servisse de referência ao desafio de gerir gerações.

\section{Análise dos Resultados}

A Promon foi fundada em r96o, por meio da aliança entre a empresa americana Procon, Inc. e a brasileira Montreal Engenharia S.A. Em I963, a Promon passou por momentos críticos, devido à conjuntura econômica vigente. Com isso, o grupo de dirigentes e funcionários se uniu e decidiu abrir mão de seus salários e passaram a retirar apenas os recursos indispensáveis à manutenção de suas famílias. Foi esse mesmo grupo que, em ı966, adquiriu o capital acionário da Promon e, em ı970, comprou as ações da Montreal.

Com o controle total da organização, esse grupo implantou o novo modelo societário, que implicava partilhar o capital da companhia entre todos os funcionários e um estilo de administração participativo, criando assim a Promon S. A. de maneira diferente de outras empresas de sociedade anônima.

O início das atividades, na década de ı960, foi marcado pela atuação na indústria petroquímica, mineração, metalurgia, energia e obras públicas. Nos anos 1970, a Promon conquistou posições nestes setores, expandindo suas operações para o exterior, e iniciou atividades ligadas a telecomunicações. A década de I980 foi pontuada pela consolidação 
da empresa nos setores em que já atuava e pelo crescimento nas áreas de telecomunicações e eletrônica. A área de telecomunicações assumiu maior destaque nos negócios da Promon nos anos I99o, sem, contudo, inibir o desenvolvimento de projetos em outras áreas.

Atualmente com sede em São Paulo, contando com empresas e escritórios em outros oito países da América Latina, possui 2.300 profissionais, sendo no Brasil cerca de r.8oo deles. A empresa mantém sua presença em engenharia e telecomunicações, e está buscando expandir sua atuação em tecnologia da informação. A Promon S.A. elabora soluções customizadas complexas de engenharia nas áreas de computação, construção civil, telecomunicação, elétrica e eletrônica, mas não realiza a implementação de tais soluções, que ocorre por meio de consórcios com outras empresas.

As particularidades da fundação da organização e do seu crescimento parecem impulsionar o seu estilo de gestão até os dias de hoje. Essa visão pode ser observada na descrição do contexto estrutural, exposta a seguir.

\section{O contexto estrutural}

Desde a fundação, a empresa transmite a ideia de "propriedade" aos funcionários, conforme explica a entrevistada:

Essa é uma empresa dos funcionários. Não tem nenhum investidor externo que tenha um centavo do capital dela. A Promon tem um modelo acionário que é administrado pelos próprios funcionários, mesmo sendo uma empresa de capital fechado. Esse modelo nasceu na década de 1970 , no período da ditadura militar. E, até hoje, nenhuma empresa copiou isso (DIRETORA DE RELAÇÕES HUMANAS E COMUNICAÇÃO - PROMON S. A.)

Com tendência a uma gestão mais participativa, o contexto estrutural tende ao sistema orgânico (BURNS; STALKER, I96I), fato que se reflete em desafios diversificados de gestão de pessoas e na maneira como a comunicação acontece.

\section{Os indícios de sistema orgânico}

A participação dos empregados no modelo acionário da empresa é voluntária, com percentual de compra igual para todos. Existe um limite e qualquer um pode alcançá-lo, sem escalonamento por nível hierárquico. O modelo guarda coerência com o princípio original de estabelecer uma comunidade de profissionais, baseada no espírito 
de cooperação. Esse modelo societário pressupõe a renovação constante do quadro de acionistas. A empresa compra as ações dos profissionais que se desligam e as coloca à disposição dos que estão chegando.

O Conselho de Administração da Promon S.A., que é a mais alta instância da organização, é responsável pela definição dos objetivos e pela orientação geral dos negócios. Os conselheiros são eleitos pelos funcionários-acionistas para mandatos de três anos. Seus integrantes necessitam ter comprovada experiência em gestão negócios e adesão aos valores e princípios da organização.

Foram criados três comitês de apoio ao Conselho de Administração: o de Estratégia, voltado à análise e ao acompanhamento da macro estratégia do grupo em todas as suas perspectivas; o de Riscos e Auditoria, dedicado à análise e ao acompanhamento da gestão dos principais riscos dos negócios e dos trabalhos das auditorias interna e independente; e o de Desenvolvimento Organizacional, orientado à discussão dos temas ligados a gente, sistema de gestão, cultura e modelo organizacional.

\section{Os desafios diversificados da gestão de pessoas}

A flexibilidade requerida do modelo pode ser verificada por meio da diversidade de desafios que a gestão de pessoas de cada uma das quatro empresas do grupo enfrenta:

A Promon Engenharia atua no mercado de engenharia e soluções integradas de infraestrutura, seus setores de atuação são: óleo e gás, mineração e metalurgia, energia elétrica, química e petroquímica, meio ambiente e determinados segmentos da indústria de manufatura. Nessa empresa, os projetos são abertos ou fechados devido a circunstâncias da conjuntura macroeconômica do país, portanto, o principal desafio é a gestão do conhecimento. Procura-se aproveitar o potencial das pessoas e o seu conhecimento acumulado enquanto desenvolvem projetos complexos relacionados à expansão da infraestrutura do país.

A Promon Logicalis é uma joint venture entre a companhia britânica Logicalis Group Limited e a Promon, que é dedicada à integração de sistemas no mercado de tecnologia da informação e comunicação, com presença na América Latina. A Promon detém $40 \%$ do capital dessa empresa e mantém a responsabilidade integral por sua gestão. Seu principal desafio é reter seus profissionais devido a duas circunstâncias: I) O 
perfil do profissional dessa área ser geralmente mais jovem e estar mais propenso a trocar de emprego caso receba uma oferta de remuneração mensal maior; 2) Normalmente, esses profissionais não estão acostumados a trabalhar na condição de formalidade do trabalho (Regime balizado pela Consolidação das Leis do Trabalho - CLT), sendo que a Promon só trabalha sob esse regime de trabalho.

A Trópico está focada no fornecimento de soluções para operadoras de telecomunicações. Trata-se de uma joint venture entre a Promon, $\mathrm{CPqD}$ e a Cisco e está na vanguarda da tecnologia para as redes de nova geração. Devido à forte concorrência com os chineses, o principal desafio é o de mudar a mentalidade de trabalho com hardware (produto) para uma mentalidade de baseada no desenvolvimento de soluções de softwares (serviço).

A Promon Novos Negócios prioriza o desenvolvimento estruturado de novos empreendimentos para o Grupo Promon. Enquanto nas outras unidades de negócio a questão técnica é o fator preponderante, nessa unidade o fundamental é o desenvolvimento de habilidades empreendedoras dos profissionais de engenharia, como, por exemplo, visão sistêmica, marketing, finanças e outras habilidades relacionadas à análise de viabilidade na introdução de inovações e expansões do portfólio da organização.

\section{A importância da inovação e a comunicação estratégica}

Na missão da organização é observado o apelo à inovação no modelo de gestão de pessoas (MEISTER; WILLYERD, 2OIO): “Empreender negócios e prover soluções de infraestrutura com aplicação consciente e inovadora de tecnologia, por meio de uma comunidade dinâmica de profissionais, criando valor para os clientes e sendo agente do processo de transformação da sociedade".

Elaborada em I970, a Carta de Campos do Jordão contém os princípios fundamentais que expressam os valores, ideais e a visão de mundo da organização. Este documento procura traduzir aos seus empregados as posturas consagradas na Promon ao longo de sua existência. A busca da excelência em todos os seus aspectos, a valorização das pessoas em sua perspectiva profissional e humana, o rigoroso padrão ético em todos os seus relacionamentos com clientes, parceiros e fornecedores, profissionais, acionistas, 
concorrência, esfera pública, sociedade e meio ambiente são alguns dos princípios que constam nesse e em outros documentos internos. Para o cumprimento de tais princípios, a comunicação é tratada como fator estratégico. Formalmente, ela ocorre por meio da intranet, publicações periódicas, eventos e murais. De acordo com a organização," a comunicação procura ser ampla, multidirecional, clara, objetiva, intensa e verdadeira e a tomada de decisão é consensual"(EXTRAÍDO DE MATERIAL CEDIDO PELA ORGANIZAÇÃO). Tais características caracterizam um sistema orgânico de empresa (BURNS; STALKER, I96I).

\section{O contexto normativo}

Os indícios de um contexto forte de gestão de pessoas são encontrados no próprio papel da área de Recursos Humanos.

\section{A criação da sensação de pertencimento}

Para a organização, o senso de pertencer é inerente ao conceito de comunidade que ela prioriza em seu modelo de gestão porque traz à consciência de que cada indivíduo é responsável pelo destino do grupo. Dessa percepção, surge o desejo de participar e contribuir ativamente para o êxito coletivo. Nesse sentido, o RH teria a seguinte atribuição:

Designamo-nos como uma comunidade de profissionais, que são proprietários da empresa. Queremos que o empregado perceba que se o resultado é atingido, é gerada uma riqueza. Se essa riqueza for alcançada, ela será distribuída entre todos. Assim, o desenvolvimento desse senso de comunidade é uma das atribuições do RH. Em outras palavras, seria “desenvolver o senso de pertencer no sentido coletivo" (EXTRAÍDO DE MATERIAL CEDIDO PELA ORGANIZAÇÃO)

Nesse sentido, o papel do RH é promover eventos e um forte contexto que possibilitem aos empregados o entendimento do que está acontecendo (BOWEN; OSTROFF, 2004; JOSHI et al., 20IO). Espera-se, dessa forma, que o empregado tome consciência de se colocar de forma ativa no contexto organizacional. Portanto, a organização espera que ele saiba lidar com a ambiguidade. E, que consiga colocar os seus interesses coletivos acima dos individuais. 
Contudo, o RH faz a distinção entre ser acionista e ser funcionário, conforme informa a entrevistada:

Essa é uma empresa dos funcionários. Não tem nenhum investidor externo que tenha um centavo do capital dela. A Promon tem um modelo acionário que é administrado pelos próprios funcionários, mesmo sendo uma empresa de capital fechado. Esse modelo nasceu na década de I970, no período da ditadura militar. E, até hoje, nenhuma empresa copiou isso (DIRETORA DE RELAÇÕES HUMANAS E COMUNICAÇÃO - PROMON S. A.)

Contudo, o RH faz a distinção entre ser acionista e ser funcionário, conforme informa a entrevistada:

Além disso, as práticas também procuram estar alinhadas aos princípios do modelo (FISCHER, 2002; LEPAK; SHAW, 2008). Por exemplo, a organização não paga comissão por vendas, porque acredita que o vendedor precisa entender que a venda dele será importante para o alcance do resultado da organização, e que se o resultado for gerado, ele será distribuído para todos. A entrevistada justifica isso dizendo que:

O vendedor não realiza a venda sozinho, ele depende do profissional técnico, então, não seria justo apenas ele receber uma comissão. Outra prática, é que os diretores não têm carro, como algumas empresas praticam, porque não faz sentido se todos os empregados são sócios, eles pagarem carro apenas para os diretores (DIRETORA DE RELAÇÕES HUMANAS E COMUNICAÇÃO - PROMON S. A.)

\section{$A$ "gestão $Y$ " das pessoas}

No modelo societário da empresa e na responsabilização por resultados, são percebidas características da gestão que são aderentes à geração $\mathrm{Y}$, por estimular um ambiente que favoreça e inquietação e contestação do cotidiano de trabalho (VELOSO, 2OI2; VELOSO, SILVA; DUTRA, 2OI2).

Segundo a entrevistada, a gestão apresenta certa flexibilidade, com características também aderentes à geração Y, contestadora de regras(COIMBRA; SCHIKMANN, 2OOI): "Nenhum dos nossos negócios tem regras muito claras. Todos aqui sabem que o futuro depende daquilo que eles quiserem que seja. Assim, aqui, a pessoa tem a responsabilidade de ajudar a construir esse futuro" (DIRETORA DE RELAÇÕES HUMANAS E COMUNICAÇÃO - PROMON S. A.)

Por ser uma empresa de alta tecnologia, os empregados são estimulados ao aprendizado contínuo dentro e fora da organização. Nesse sentido, o desenvolvimento da 
carreira depende do próprio empregado, conforme explicado:

A Promon não é uma empresa paternalista e não vai dizer tudo o que o empregado precisa aprender, mas, vamos prover condições para discussão sobre o seu desenvolvimento com as demais pessoas da organização. A Promon é um projeto aberto, que é moldado a partir do interesse que as pessoas têm de moldá-lo (DIRETORA DE RELAÇÕES HUMANAS E COMUNICAÇÃO - PROMON S. A.)

A necessidade de desenvolvimento, característica dos profissionais da geração Y (VELOSO; DUTRA; SILVA, 20I2), é atendida no preenchimento de vagas, pois a Promon privilegia o aproveitamento de pessoal interno como uma forma de propiciar oportunidades de crescimento profissional.

A busca por autonomia, também típica dos da geração Y(VELOSO, 2OI2; VELOSO; SILVA; DUTRA, 2OI2) é percebida no programa de educação corporativa e nas decisões sobre salários.

Na educação corporativa, os profissionais podem fazer sua autoproposição de treinamento a partir de uma grade de referências. A validação dos planos de capacitação individuais é realizada pelos centros de competência e diretoria. O apoio do mentor é essencial neste momento, sendo, muitas vezes, requisitado a dar seu parecer frente aos cursos solicitados pelo profissional.

Quanto aos salários nominais, a Promon procura mantê-los salários nominais alinhados com os de empresas de alto padrão de gestão de pessoas e com perfil equivalente de profissionais e busca proporcionar por meio da participação nos lucros e benefícios o posicionamento da remuneração no terceiro quartil da curva salarial do mercado. O lucro gerado pela organização é distribuído em três partes. A primeira, sob a parte dos dividendos, que são distribuídos conforme a proporção de cotas de cada empregado. A segunda, sob a Participação nos Lucros e Resultados (PLR). Já a terceira é um percentual reinvestido no capital para melhorar o preço da ação; em capacitação e em novas metodologias de trabalho.

Os resultados das pesquisas salariais são divulgados a todos os funcionários em encontros com RH e na intranet. Nessa linha, a Promon introduziu o procedimento de autoproposição salarial no processo de revisão de salários. Tal prática pretende assegurar que os profissionais pesquisem valores e se posicionem, justificando os parâmetros utilizados em relação a seu salário. Dessa forma, pode haver casos de 
negociação entre funcionário e atribuidor (coordenador de disciplinas e chefes).

Além dessas ações, a inquietação e a necessidade de reconhecimento, típicos da geração Y (VELOSO, 2OI2; VELOSO; SILVA; DUTRA, 2OI2), podem ser associados às ações da organização que atribuem importância de mecanismos de reconhecimento não monetário, como avaliações de desempenho dos líderes e dos membros dos times. Também é reconhecido o fato de que, em certas situações, a melhor recompensa é o oferecimento de um novo e atraente desafio. Na opinião da diretora de RH, esse composto remuneratório tem conseguindo, inclusive, incorporar uma visão de longo prazo nos jovens profissionais da organização.

Para tratar os fatores que afetam o bem-estar, motivação e satisfação, a Promon implantou seu programa de qualidade de vida, algo que também faz parte dos anseios da geração Y (VELOSO; DUTRA; SILVA, 2OI2). O programa está estruturado reconhecendo três temas: comunidade e lazer, saúde e atividade física. A organização acredita que promover condições de trabalho que propiciem o equilíbrio entre a vida profissional, pessoal e familiar de todos os seus profissionais é um dos fatores a serem perseguidos pela gestão de pessoas. Nesse sentido, também há o regime de horário móvel proporciona ao profissional escolher, em acordo com a sua chefia e dentro de períodos prefixados, em que momento iniciar e encerrar seu expediente.

As associações da gestão da organização às características da geração Y não significam que essa forma de gerenciar pessoas não seja adequada às outras gerações (X e Baby boomers). Tais associações apenas indicam que certas organizações, como a Promon, desde a sua fundação, apresentam um tipo de gestão que faz parecer que estas “nasceram Y". Esse fato, certamente, se reflete na maneira como a gestão das gerações acontece.

A gestão das gerações

Especificamente, no que diz respeito à gestão das gerações a entrevistada manifestou o seguinte raciocínio: "Se formos analisar as características dos profissionais seniors, provavelmente, teriam as mesmas características dos jovens de hoje” (DIRETORA DE RELAÇÕES HUMANAS E COMUNICAÇÃO - PROMON S. A.)

Essa frase da entrevistada, além das particularidades da gestão das gerações, 
apresentadas a seguir, mostra que a prioridade dessa gestão não tem relação direta com a idade e sim com os papéis que a pessoa exerce em determinado momento (JOSHI et al., 20IO). Dessa forma, algumas ações organizacionais promovem a interação entre pessoas de diferentes idades.

\section{A interação entre as gerações para o aprimoramento dos papéis funcionais}

No aprendizado on the job, ou seja, nos projetos desenvolvidos, foi relatada a intenção de promover a mistura de gerações, pelos seguintes motivos:

Os jovens são mais arrojados, se arriscam mais e têm menos medo de errar. Isso é importante para nós, quando consideramos o perfil empreendedor de empregado que precisamos. Os mais velhos possuem conhecimento que não se conquista com um ano de trabalho. Existem projetos que precisam de pessoas com experiência de mais de 20 anos de estudo. Assim, o mix é saudável e buscamos fazer isso até em grupos de estudo. (DIRETORA DE RELAÇÕES HUMANAS E COMUNICAÇÃ̃O - PROMON S. A.)

Outro exemplo do estímulo a essa interação, é criação da entidade sem fins lucrativos, denominada de Instituto de Tecnologia Promon (ITP), cujo propósito é ser um polo antecipador e preparador do futuro por meio da geração e difusão do conhecimento tecnológico nos setores de energia, desenvolvimento sustentável e tecnologia da informação e comunicação. Em 2OII, foram constituídos cinco “observatórios tecnológicos”. Os observatórios são estruturados como redes, integradas por núcleos de jovens profissionais e grupos de especialistas seniores. Nessa abordagem, os profissionais seniores contam com o apoio de jovens talentos que também atuam como tutores dos participantes dos cursos. Em síntese, o os conhecimentos produzidos ou operacionalizados são transformados em módulos de ensino a distância via internet voltados ao desenvolvimento e treinamento dos profissionais.

\section{As adaptações das gerações a diferentes papéis funcionais}

Na convivência entre as gerações na Promon pode ser identificada a função de promoção da adaptação das pessoas de idades diversas a necessidades relativas aos seus papéis funcionais. Nesse sentido, a entrevistada relatou o seguinte:

Os jovens trabalham com mais facilidade com as ferramentas móveis e colaborativas do que os mais velhos. Por isso, tentamos encontrar meios para adaptar a gestão dos mais velhos a essa nova realidade, porque a otimização do espaço físico é algo 
importante para o nosso trabalho... Também há casos que o chefe mais velho reclama que o jovem passa muito tempo conversando pela internet com outras pessoas fora do ambiente de trabalho. Outra questão é se o jovem tem o chefe como uma referência e se é motivo de orgulho trabalhar com ele. (DIRETORA DE RELAÇÕES HUMANAS E COMUNICAÇÃOO - PROMON S. A.)

\section{As gerações e a administração dospapéis funcionais transitórios}

O fato de que a Promon trabalha, predominantemente, com projetos explica parte da gestão das gerações focada em papéis funcionais (JOSHI et al., 2OIO). Foi organizada uma estrutura multidisciplinar que é seguida por todos os projetos da organização. Nela, cada projeto está sob o comando de um diretor que é responsável por sua gestão. Entretanto, todo projeto possui uma natureza transitória, assim, a cada funcionário é atribuído um nível profissional e um cargo ou função. O nível profissional é um atributo do profissional, traduz a sua senioridade, evoluindo, portanto, com seu aprendizado, maturidade e experiência. A função ou o cargo traduz o papel que o profissional está desempenhando no momento.

Para administrar o nível profissional dos empregados, a organização montou os Centros de Competências, que são entidades virtuais onde acontece a gestão do conhecimento. Esses centros estão alinhados às competências core da Promon, que são: engenharia; gestão de empreendimentos; gestão de fornecimentos e construção e montagem.

Cada centro de competência é composto por áreas de conhecimentos, ou, disciplinas. Por sua vez, cada disciplina possui um coordenador, que, geralmente, é um profissional com perfil de atuação técnico ou gerencial relevante naquela competência. $\mathrm{O}$ coordenador de disciplina também tem o papel de gestor do conhecimento, com três atribuições básicas: I) planejamento do efetivo de profissionais; 2) capacitação dos empregados; 3) disseminador do conhecimento. Além dessas atribuições, o coordenador de disciplina tem poder de decisão sobre a demissão e estabelece a remuneração fixa dos empregados, pois é ele quem melhor conhece a maturidade profissional dos empregados, sendo também responsável pela integração na disciplina e por uma ambientação técnica que ocorre na primeira semana de trabalho. 


\section{Desenvolvimento dos jovens para novos papéis funcionais}

A Promon, de forma geral, tem entre suas preocupações na gestão das gerações o desenvolvimento dos jovens para seus papéis, e, como tantas outras organizações, promover a gestão da geração Y. Em relação à participação dos jovens no processo de gestão, a entrevistada relatou o seguinte:

Acredito que os jovens de hoje não têm o mesmo apego às organizações do que os profissionais de antigamente. Eles têm apego com o propósito, se conseguirmos propor desafios que os façam envolvidos, tudo bem, senão, o vínculo com a empresa é fragilizado. (DIRETORA DE RELAÇÕES HUMANAS E COMUNICAÇÃO - PROMON S. A.)

A necessidade de desenvolvimento desses profissionais é atendida pelo programa de mentoração. De acordo com os critérios definidos pelo RH, a organização define a lista dos profissionais aptos a exercerem a função de mentor, em geral, profissionais seniores, com mais de um ano de empresa. Com base nessa lista, cada profissional pode escolher seu mentor. Anualmente, os mentores e mentorados devem participar do treinamento que aborda o processo de mentoração, sua importância para a organização e para o profissional e a melhor forma de realizar todo o processo.

Com o apoio do mentor, o mentorado deve traçar um plano que envolve recomendações de ações para o desenvolvimento e aproveitamento do potencial e para futuras oportunidades de crescimento, como treinamentos formais e on the job, visitas, estágios e outras ações orientadas pelos planos estratégicos da organização, levando em conta as potencialidades e interesses individuais. Essas ações devem ser validas pelos respectivos coordenadores de disciplina e centros de competência.

Paralelamente, os programas de estágio e jovem aprendiz constituem parte do processo de formação, manutenção e desenvolvimento de recursos humanos e tem por objetivo suprir a organização de jovens profissionais com alto potencial.

Para promover a oportunidade de transição entre papéis funcionais, é promovido o alinhamento entre a experiência dos gestores, os princípios e cultura organizacionais, Os processos e projetos de uma empresa pode se tornar um dos fatores-chave para seu desenvolvimento. Pensando nisso, a Promon estruturou o PDG - Programa de Desenvolvimento de Gestores, que oferece conceitos, ferramentas e práticas para promover o desenvolvimento de novas percepções em seus gestores. 
Paralelamente detecta-se o fato de que, quando o jovem cobra excessivamente a organização, espera-se uma contrapartida:

Também podemos devolvê-la (a cobrança) para ele, porque temos um ambiente que favorece isso. Por exemplo, se o jovem reivindica algo à organização, nós também queremos que ele proponha algo para nós. Agindo dessa maneira, acredito que não estamos tendo muitas perdas e conseguindo ter uma boa relação com eles. (DIRETORA DE RELAÇÕES HUMANAS E COMUNICAÇÃO - PROMON S. A.)

De forma geral, nota-se que a gestão de pessoas da Promon é complexa e apresenta flexibilidade compatível com os desafios do negócio. A gestão das gerações baseada em papéis funcionais mostra-se adequada a esse cenário.

\section{Considerações Finais}

Em uma organização com indícios de operar em um sistema orgânico, é possível notar a importância da gestão de pessoas para suportar diferentes desafios associados a cada um dos contextos. Paralelamente, foi possível observar as três características de um forte sistema de gestão de pessoas, ou seja, sua distinção das demais práticas organizacionais, a existência de um comitê de desenvolvimento organizacional no Conselho de Administração é a maior evidência dessa característica. A consistência pelo o alinhamento das práticas aos princípios do modelo de gestão de pessoas. E, por fim, a busca de estabelecer consenso nos empregados sobre quais comportamentos levam a determinadas consequências, cujo maior exemplo é o senso de propriedade da Promon (BOWEN; OSTROFF, 2004)

Nesse contexto da gestão de pessoas, a gestão das gerações tem seu desafio voltado à predominância dos papéis funcionais em relação à idade. $\mathrm{O}$ fato da empresa parecer ter sido fundada nos anos de 1960 com características atuais da geração Y.e que permanecem até hoje, possibilitam a promoção da convivência entre as gerações, voltada ao estímulo ao desenvolvimento constante das pessoas.

Embora existam indícios das diferenças geracionais baseadas em idade no Brasil (VELOSO, 20I2; VELOSO; SILVA; DUTRA, 20I2;), a análise do caso da Promon mostrou que tais diferenças não implicam diretamente adaptações na gestão de pessoas, o que destoa das sugestões dos teóricos do assunto (LEPAK; SHAW, 2008; MCGUIRE et al., 2007;MEISTER; WILLYERD, 2OIO). A organização possui um contexto de 
gestão de pessoas que apresenta a tendência de orientar o comportamento humano em coerência com o modelo de gestão organizacional, mitigando, assim, os efeitos das diferenças geracionais baseadas em idade.

Como principal limitação do estudo, o uso da abordagem de estudos de casos não possibilita a generalização prática dos resultados; essa técnica apenas possibilita a generalização teórica acerca de organizações que buscam se destacar em termos de gestão de pessoas (EISENHARDT, I989).

Para ampliar os resultados desta pesquisa, recomenda-se a realização de futuros estudos em organizações com características diversas, especialmente as públicas e do terceiro setor, tendo em vista as suas peculiaridades e desafios na criação de um contexto forte do sistema de gestão de pessoas (BOWEN; OSTROFF, 2O04; JOSHI et al., 2OIO).

De forma geral, por meio deste estudo, nota-se que o contexto em que a gestão de pessoas acontece, influencia a gestão das gerações. Tal influência parece impossibilitar a criação de apenas um padrão para tal gestão, tornando ainda mais desafiadora a tarefa e promover a convivência inevitável entre as gerações.

\section{Referências}

BARDIN, L. 2002. Análise de conteúdo, Ed. 7O, Lisboa, 2002.

BERVIAN, P. A.;CERVO, A. L.;SILVA, R. Metodologia Científica, Pearson Education do Brasil, São Paulo, 2007.

BOXALL, P.; PURCELL, J. Strategic human resource management: Where have we come and where we should be going? International Journal of Management Reviews, v. 2, n. 2, pp. I83- 203, 2000.

BOWEN, D. E.; OSTROFF, C. Understanding HRM-firm performance linkages: the role of the "strength" of the HRM system. Academy of Management Review, v. 29, n.2, pp. 203-22I, 2004.

BURNS, T.; STALKER, G. M. The management of innovation, Tavistock, London, I96I.

COIMBRA, R. G. C.; SCHIKMANN, R. A geração net. XXV Enanpad-Encontro Nacional da Anpad,Campinas, $200 \mathrm{I}$.

DEMO, G. Política de gestão de pessoas nas organizações: papel dos valores pessoais e da justiça organizacional, Atlas, São Paulo, 2008.

EISENHARDT, K. M. Building theories from case study research. Academy of Management Review, V.I4, n.4, pp.532- 55O, I989.

FISCHER, A. L. Um resgate conceitual e histórico dos modelos de gestão de pessoas. In M. T. L. FLEURY (Org.). As pessoas na organização (pp. II-33), Gente, São Paulo, 2002. 
FIUZA, G. D. Políticas de gestão de pessoas, valorespessoais e justiça organizacional. Revista de Administração Mackenzie- RAM, v. II, n. 5, pp. 55-8I, 2010.

GIBBERT, M.; RUIGROK, W.; WICKI, B. What passes as a rigorous case study? Strategic Management Journal,v. 29, n.I, pp. I465-I474, 2008.

GIL, A. C. Como elaborar projetos de pesquisa. 5 ed, Atlas, São Paulo, 2010.

IPEA - Instituto de Pesquisa Econômica Aplicada. PNAD 2012 -Tendências demográficas. Comunicados do IPEA, n. I57. Brasília: IPEA, II de outubro de 2012.

JOSHI, A.; DENCKER, J. C.; FRANZ, G.;MARTOCCHIO, J. J. Unpacking generational identities in organizations. Academy of Management Review, v. 35, n.3, pp. 392-4I4, 2010.

LEPAK, D. P.; SHAW, J. D.Strategic HRM in North America: Looking to the future. The International Journal of Human Resource Management, v.I9, n.8, pp. I486-I499, 2008.

MARTÍN-ALCÁZAR, F.; ROMERO-FERNÁNDEZ, P. M.; SÁNCHEZ-GARDEY, G. Strategic human resource management: Integrating the universalistic, contingent, configurational and contextual perspectives. The International Journal of Human Resource Management, v.I6, n.5, pp.633-659, 2005.

MCGUIRE, D.;TODNEM, R.; HUTCHINGS, K. Towards a model of human resource solutions for achieving intergenerational interaction in organisations. Journal of European Industrial Training,v.3I, n.8, pp.592-6o8, 2007.

MEISTER, J. C.; WILLYERD, K. The 2oro Workplace: How innovative companies attract, develop, and keep tomorrow’s employees today, Harper Business, New York, 20 oro.

MISCHEL, W. Toward a cognitive social learningreconceptualization of personality.Psychological Review, v.8o, n.4), pp.252-283, 1973 .

MOZZATO, A. R.; GRZYBOVSKI, D. Análise de Conteúdo como Técnica de Análise de Dados Qualitativos no Campo da Administração: Potencial e Desafios.Revista de Administração Contemporânea - RAC, v.I5, n.4, pp.73I-747, 20 II.

PARRY, E.; URWIN, P.Generational Differences in Work Values:A Review of Theory and Evidence .Internationa IJournalof Management Reviews, v. I3, n.I, pp.79-96, 2 OII.

SILVA, A. B.; NETO, J. R. Perspectiva multiparadigmática nos estudos organizacionais, In:GODOI, C. K.; BANDEIRA-DE-MELLO, R.; SILVA, A. B. (Org). Pesquisa Qualitativa em Estudos Organizacionais: Paradigmas, Estratégias e Métodos, 2ed., Saraiva, São Paulo, 2010.

SILVA, R.C. ; LAIZO, A.; VELOSO, E.F. R.; DUTRA, J. S. Políticas e práticas de flexibilização para o trabalho: os impactos na percepção dos empregados sobre equilíbrio entre vida e trabalho e crescimento profissional. In: XXXXIV Enanpad-Encontro Nacional da Anpad,Rio de Janeiro, 2010.

VELOSO, E. F. R.; DUTRA, J. S.;\& NAKATA, L. E. Percepção sobre carreiras inteligentes: Diferenças entre as gerações Y, X e Baby boomers.In: XXXII Enanpad-Encontro Nacional da Anpad,Rio de Janeiro, 2008.

VELOSO, E. F. R. É possível negar a existência da geração Y no Brasil? Revista Organizações \& Sociedade, v. I9, n.63, pp. 745-747, 2012. 
VELOSO, E. F. R.; SILVA, R. C.; DUTRA, J. S.Diferentes Gerações e Percepções sobre Carreiras Inteligentes e Crescimento Profissional nas Organizações. RevistaBrasileira de Orientação Profissional, v. I3, n.2, pp. 197-207, $20 \mathrm{I} 2$.

WERBEL, J. D.; DEMARIE, S. M.Aligning strategic human resource management and personenvironment fit, Human Resource Management Review, v. I5, pp.247-262, 2005.

WESTERMAN, J. W.; YAMAMURA, J. H.Generational preferences for work environment fit: Effects on employee outcomes.Career Development International, v. I2, n. 2, pp. I5O-I6I, 2007.

WOOD JR, T.; TONELLI, M. J.; COOKE, B.Colonização e neocolonização da gestão de recursos humanos no brasil (1950-20IO).Revista de Administração de Empresas- RAE, v. 5I, n.3, pp. 232-243, 2 OII.

YIN, R.K. 2OoI.Estudo de caso - planejamento e métodos, Bookman, Porto Alegre.

ZEMKE, R.;RAINES, C.; FILIPCZAK, B. Generations at work: Managing the clash of veterans, boomers, xers, and nexters in your workplace. Nova York: AMACOM, 2000. 